\title{
Biosynthesis and Characterization of Silver Nanoparticles using Wheatgrass Extract and Assessment of their Anticandidal Activity
}

\author{
SANGEETA KAMRADGI, SUHASINI ANGANELLIKAR, SHANKARAVVA BABANAGARE AND M V GUNAGAMBHIRE \\ Department of Botany, Gulbarga University, Kalaburagi, Karnataka 585106, India
}

Kamradgi et al.: Synthesis of Silver Nanoparticles from Wheatgrass Extract

\begin{abstract}
Wheatgrass extract was used for eco-friendly extracellular synthesis of silver nanoparticles. Stable silver nanoparticles were formed by treating the wheatgrass extract with aqueous silver nitratesolution as reducing agents. Ultraviolet-visible spectroscopy was used to confirm the presence of silver nanoparticles. The $\mathrm{X}$-ray diffraction analysis exhibited characteristic peaks signifying the crystalline nature of nanoparticels. The particle size and the involvement of various biomolecules in the synthesis of silver nanoparticles were determined using Atomic force microscopy and Fourier transform infrared spectroscopy, respectively. The particle structure was studied by scanning electron microscopy and the elemental silver present in reaction mixture was confirmed by Energy dispersive x-ray. The nanoparticles were tested for their anticandidal activity against Candida albicans MTCC3017, Candida albicans MTCC1637, Candida albicans MTCC183, Candida tropicalis MTCC230 and Candida glabrata MTCC3814 and determined their minimum inhibitory concentration.
\end{abstract}

Key words: Silver nanoparticles, wheatgrass, anticandidal activity, Candida species

Wheat (Triticum aestivum L.) is one of the most important cereals in the world belonging to Graminaceae family; it has been an integral part of Indian culture for thousands of years and has been known to have outstanding healing properties ${ }^{[1]}$. It is one of the major staple food for nearly $35 \%$ of the world's population, grown in 102 countries, covers 220.69 million hectares of land, accounting about $32 \%$ of the total cultivated land of the world ${ }^{[2]}$. Wheatgrass has a great therapeutic potential due to the presence of many biomolecules including chlorophyll, vitamin A, C, E and B complex, bio flavonoids, minerals (Calcium and Magnesium), iron and 17 amino acids including 8 essential ones ${ }^{[3]}$. Wheatgrass juice provides more energy by fulfilling nutritional deficiencies and removes wastes that clog cells, blood, tissues and organs ${ }^{[4]}$ and it could be an effective alternative of blood transfusion in terminally ill cancer patients. Recently, the Indian researchers examined the reduction in blood transfusion requirement up to $40 \%$ with no adverse effect in children with thalassemia, who consumed $100 \mathrm{ml}$ of wheatgrass juice per day ${ }^{[5]}$. The Indian traditional folk and Ayurvedic medicine, reveals increase in hemoglobin levels in

*Address for correspondence E-mail: gmvidyasagar@gmail.com

May-June 2021 thalassaemic and myelodysplastic patients who use aqueous extract of 7-8 d old germinated wheat seeds ${ }^{[6-9]}$.

Nanotechnology is referred as the term for fabrication, characterization, manipulation and application of structure by controlling shape and size at the nanoscale. It is emerging with its applications in science and technology for the purpose of manufacturing new materials. Nanoparticles could reach a biological target of interest by having a small size and offers a great possibility for biomedical applications, not only to deliver pharmaceutics, but also to be used as novel diagnostic and therapeutic approaches ${ }^{[10]}$. In recent years, many environment friendly methods have been employed for the synthesis of nanoparticles. The biological methods of silver nanoparticle synthesis using biological entities like bacteria ${ }^{[11]}$, yeast ${ }^{[12]}$, fungi ${ }^{[13]}$ and plants ${ }^{[14]}$ were reported. Over the past few This is an open access article distributed under the terms of the Creative
Commons Attribution-NonCommercial-ShareAlike 3.0 License, which
allows others to remix, tweak, and build upon the work non-commercially,
as long as the author is credited and the new creations are licensed under
the identical terms Indian J Pharm Sci 2021;83(3):515-522 
decades, the use of plants in medicine and industry has been significantly growing in the world, although the potential of higher plants and crops as source for this purpose is still largely unexplored ${ }^{[15]}$.

Candida is the mostcommon opportunistic human fungal pathogen causing diseases ranging from superficial mucosal to life-threatening systemic infections ${ }^{[16-18]}$, currently ranked by the Center for Disease Control as the third most commonly isolated bloodstream pathogen in hospitalized patients with a mortality rate of up to $50 \%{ }^{[19-21]}$. The availability of antifungal agents for the treatment of fungal infections is significantly lower with limitations related to their spectrum of activity and mode of action. Therefore, new and safer antifungal drugs are very much in need to combat the Candida infections. Silver ions have long been known to exert a strong inhibitory and bactericidal effect as well as possess a broad spectrum of antimicrobial activities ${ }^{[22]}$. The present studies have been conducted to understand the efficacy of silver nanoparticles (AgNPs) produced by aqueous wheatgrass extract against $C$ andida species.

\section{MATERILS AND METHODS}

\section{Collection and preparation of plant material:}

Fresh leaves of $15 \mathrm{~d}$ old wheatgrass were collected from the local Rajapur area near horticulture centre, Kalaburagi, Karnataka, India. The fresh wheatgrass was washed in tap water for several times to remove the dust particles and shade dried for 4-5 d. The dried wheatgrass material was ground and sieved to form a powder. $10 \mathrm{~g}$ of powder was boiled in $90 \mathrm{ml}$ of double distilled water and filtered. The filtrate thus obtained was used as plant extract for the synthesis of AgNPs.

\section{Synthesis of AgNPs:}

$100 \mathrm{ml}$ of $1 \mathrm{mM}$ of silver nitrate $\left(\mathrm{AgNO}_{3}\right)$ solution was mixed with equal volumes of freshly prepared dry powdered aqueous wheatgrass extract (1:1) in $250 \mathrm{ml}$ of Erlenmeyer flask and incubated for $24 \mathrm{~h}^{[23]}$.

\section{Characterization of silver nanoparticles:}

After $24 \mathrm{~h}$ of incubation, the solution was subjected to UV-visible spectrophotometer (BL Elico 200 Double beam Biospectrophotometer) and recorded the spectral peaks. The X-ray diffraction (XRD) spectroscopy (Rigaku-Ultima-IV) reveals the phase variety and grain size of silver nanoparticles. The Atomic force microscopy (AFM) was employed to study the size, shape, absorption, structure, dispersion and aggregation of nanomaterials. The chemical nature of silver nanoparticles was studied by Fourier transform infrared spectroscopy (FTIR) (NICOLET 6700). The purified and dried AgNPs mixed with Potassium bromide $(\mathrm{KBr})$ to obtain a pellet and the spectrum was evaluated at $4000-400 \mathrm{~cm}^{-1}$ using FTIR spectroscopy. The morphology of silver nanoparticles was studied using Scanning electron microscopy (Quanta 200 FEG SEM) and confirmed the presence of elemental silver in the solution by Energy dispersive X-ray (EDX) spectroscopy in conjunction with Scanning electron microscopy (SEM).

\section{Anti-candidal activity of silver nanoparticles:}

The silver nanoparticles synthesized by wheatgrass aqueous extract were tested for anti-candidal activity against five different clinical isolates of $C$. albicans MTCC3017, C. albicans MTCC1637, C. albicans MTCC183 C. tropicalis MTCC230 and C. glabrata MTCC3814 (Microbial type culture collection and gene bank, Chandighar, India) using agar well diffusion $\operatorname{method}^{[24]}$. A $20 \mathrm{ml}$ of YPDA (Yeast extract-1 g, peptone-2 $\mathrm{g}$, dextrose-2 $\mathrm{g}$, agar- $1.5 / 100 \mathrm{ml}$ of distilled water) medium was poured into sterilized petri plates and freshly grown $24 \mathrm{~h}$ old Candida cultures were seeded on YPDA medium. The synthesized AgNPs solution was centrifuged at $15000 \mathrm{rpm}$ for $15 \mathrm{mins}$, obtained residue was collected and dried. About $10 \mathrm{mg} /$ $\mathrm{ml}$ of dried AgNPs was dissolved in $5 \%$ of dimethyl sulphoxide (DMSO) was used as a test sample. The $5 \mathrm{~mm}$ diameter of 5 wells were prepared with the help of sterilized cork borer and wells were loaded with newly synthesized AgNPs $(50 \mu \mathrm{l}$ and $100 \mu \mathrm{l})$, fluconazole $(10 \mathrm{mg} / \mathrm{ml}$ of $5 \%$ DMSO) as positive control, DMSO and $\mathrm{AgNO}_{3}$ as a negative control. The plates were incubated at $28^{\circ}$ for $24 \mathrm{~h}$ and examined for the zone of inhibition. The mean value for each organism was recorded and expressed in millimeter $(\mathrm{mm})^{[23]}$.

\section{Minimum inhibitory concentration (MIC) of synthesized AgNPs:}

The MIC of synthesized silver nanoparticles was determined using the plate count method against five Candida species. $10 \mathrm{ml}$ of $1 \%$ YPG (Yeast extract-1 $\mathrm{g}$, peptone- $1 \mathrm{~g}$, glucose- $1 \mathrm{~g} / 100 \mathrm{ml}$ of distilled water) broth was inoculated with $10^{5} \mathrm{cfu} / \mathrm{ml}$ of each Candida cell and cultured in shaking incubator at $28^{\circ}$ for 24 h. The two fold diluted $(2,4,8,16,32,64,128$ and $256 \mu \mathrm{l} / \mathrm{ml}$ ) AgNPs were mixed with $100 \mu 1$ of $10^{5} \mathrm{cfu} / \mathrm{ml}$ cultured medium, made the final volume $1 \mathrm{ml}$ by adding $1 \%$ YPG broth and incubated at $28^{\circ}$ for $24 \mathrm{~h}$. After incubation the medium was spread on the petriplates 
containing $1 \%$ YPG agar medium. The plates were incubated at $28^{\circ}$ for $24 \mathrm{~h}$ and the numbers of colonies grown on the agar were counted ${ }^{[25]}$.

\section{RESULTS AND DISCUSSION}

The synthesis of silver nanoparticles was observed by visual observation of color change in plant extract (right Erlenmeyer flask) from pale yellowish to cherry red within $1 \mathrm{~h}$ after the addition of $\mathrm{AgNO}_{3}$ (fig. 1). After $24 \mathrm{~h}$ of incubation at $35^{\circ}$, the changes in color to colloidal brown assured the production of silver nanoparticles in sample mixture (left Erlenmeyer flask). Kowshik et al., reported that the reduction of silver nitrate into silver nanoparticles is clearly visible when the sample solution changes its color from colorless to brown with increase color intensity and also reported the brown color of the sample solution was due to the excitation of AgNPs in the surface plasmon vibration ${ }^{[12]}$. That was initial sign of synthesis of silver nanoparticles can be detected by naked eyes has been reported from early reports ${ }^{[26]}$. The UV-Visible spectra of silver nanoparticles gave a Plasmon resonance band and absorption peak at $400 \mathrm{~nm}$ (fig. 2). The early reports on silver nanoparticles showed the absorption peaks in visible range of $434 \mathrm{~nm}^{[27]}, 410 \mathrm{~nm}^{[28]}, 420 \mathrm{~nm}^{[29]}, 436-446 \mathrm{~nm}^{[30]}$ and $423 \mathrm{~nm}^{[15]}$. Fig. 2 showed a sharp single peak at $400 \mathrm{~nm}$ of visible spectra and confirms the reduction of $\mathrm{Ag}$ ions into $\mathrm{Ag}$ nanoparticles in wheatgrass aqueous extracts. The intensity of absorption peak and color intensity increase with the duration of incubation ${ }^{[31]}$. The size of silver nanoparticle range 5-10 $\mathrm{nm}$ absorbs UV-visible light near $420 \mathrm{~nm}^{[32]}$. According to Rong et al. the smaller nanoparticles possess less single surface Plasmon resonance that results in blue shift. In the present study, the absorption peak recorded from UV-visible spectra at $400 \mathrm{~nm}$ reveals the size $(<20 \mathrm{~nm})^{[33]}$ of synthesized AgNPs and supports the report of Mahmut et al. ${ }^{[15]}$. The XRD peaks at 28.0, 32.0, 38.0, 42.0, 48.0, 57.0, 65.0, 68.0 and 86.0 confirm the crystalline nature of nanoparticles and incorporated with organic compounds on the surface of silver atoms. The distinct broader diffraction peaks attributes smaller particle size. The diffraction peaks observed in $2 \Theta$ range of $20-80^{\circ}$ consequently, confirm that the nanoparticles have face center cubic (FCC) structure (fig. 3). AFM determines particle size between 20 to $85 \mathrm{~nm}$ (fig. 4). The possible biomolecules present in WG extract responsible for the reduction of $\mathrm{Ag}+$ ions to AgNPs were recorded and mentioned their respective functional groups (fig. $5 \&$ Table 1). FTIR pattern of synthesized silver nanoparticles revealed the presence of various organic compounds with different functionalities. A broader peak formed at $3382.45 \mathrm{~cm}^{-1}$ showed the presence of $-\mathrm{OH}$ stretching vibration band. The O-H stretching carboxylic acid was observed at $2924.50 \mathrm{~cm}^{-1}$. The peaks at $2854.95 \mathrm{~cm}^{-1}, 1630.46$

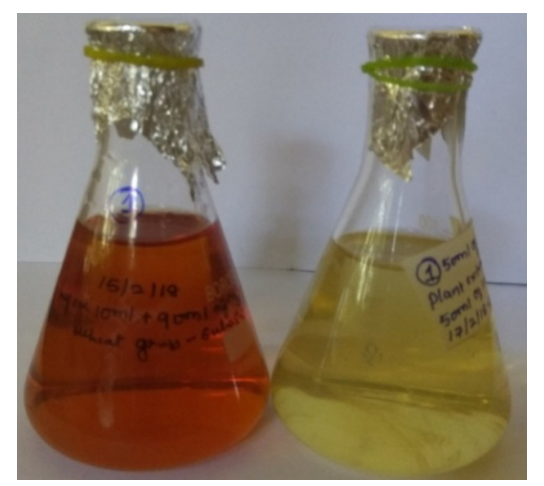

Fig. 1: Wheatgrass (WG) aqueous extract treated with $\mathrm{AgNO}_{3}$ Note: The right flask containing wheatgrass aqueous extract without $\mathrm{AgNO}_{3}$ and left flask showing color changes with $1 \mathrm{M}$ $\mathrm{AgNO}_{3}$ after $24 \mathrm{~h}$ of reaction.

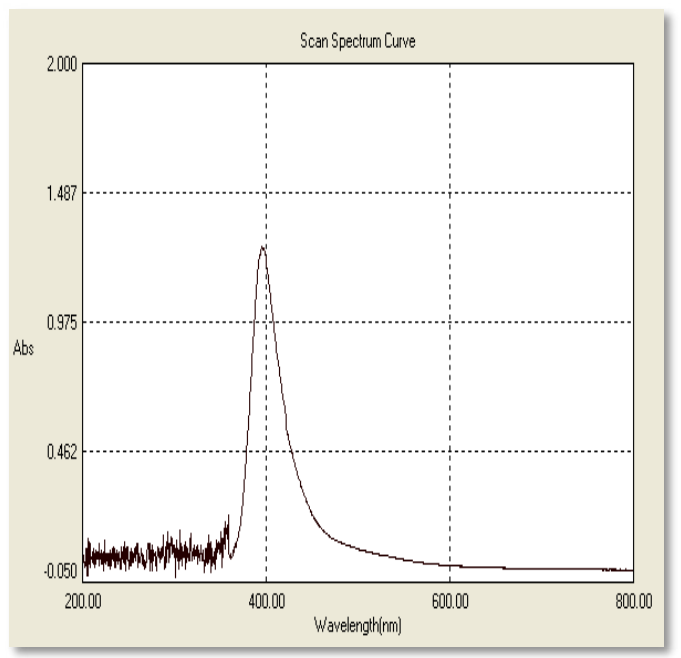

Fig. 2: UV-vis spectra of AgNPs

Note: UV-vis spectra of AgNPs obtained by the reduction of $\mathrm{AgNO}_{3}$ into AgNPs.

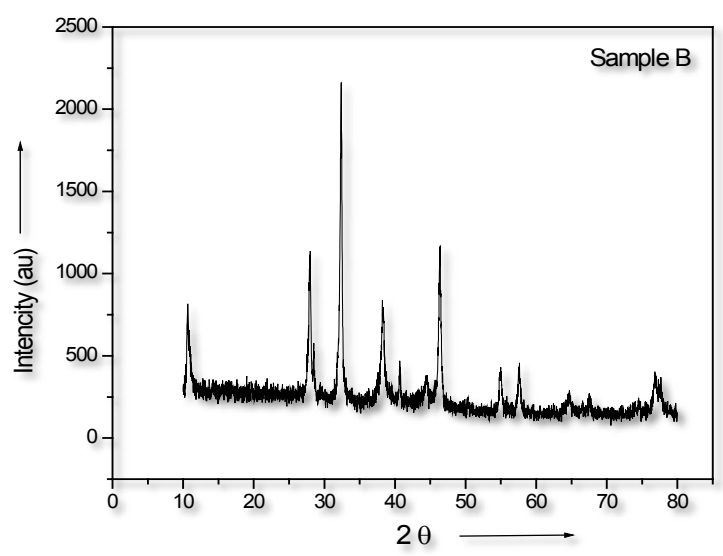

Fig. 3: XRD pattern of synthesized AgNPs. 
$\mathrm{cm}^{-1}$ and $1384.16 \mathrm{~cm}^{-1}$ showed the presence of $\mathrm{ZnO}$ particles, primary amides and monosubstituted alkynes respectively. The band at $1052.05 \mathrm{~cm}^{-1}$ assigned Si-OSi symmetric stretching vibrations of polypeptides and proteins. An alkaline stretching and bending molecular vibrations used to obtain the information about surface topography and composition. The morphological view of synthesized silver nanoparticles by SEM analysis reveals the spherical shape of silver nanoparticles with particle size below $100 \mathrm{~nm}$ (fig. 6). The presence of Ag metals in reaction mixture analyzed by EDX confirms the synthesis of silver nanoparticles (fig. 7). EDX in conjugation with SEM determined the elemental composition of the silver nanoparticles. Nowadays

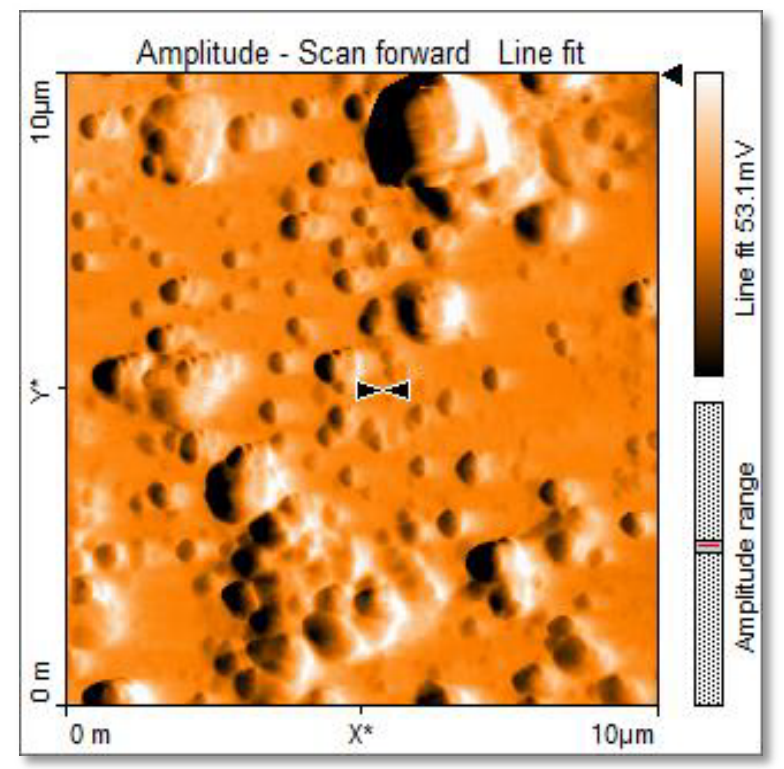

Fig. 4: AFM images of AgNPs biosynthesis of silver nanoparticles has gained more popular and advanced among the biologists, chemists and biotechnologist.

The anticandidal activity of silver nanoparticles carried out against five different strains of Candida using agar well diffusion method showed highest $15 \mathrm{~mm}$ zone of inhibition at $50 \mu \mathrm{l}$ concentration against $C$. albicans MTCC1637 and found equal zone of inhibition by standard fluconazole indicates the similar efficacy of synthesized AgNPs whereas $\mathrm{AgNO}_{3}$ solution has shown least inhibitory activity against all tested Candida spp. compared with AgNPs. The Lowest 9 and $10 \mathrm{~mm}$ zone of inhibition was recorded against $C$. tropicalis MTCC230 and C. glabrata MTCC3814 respectively (Table 2). The low activity does not mean that the silver particles do not have any activity; probably it will show the activity with high concentration of AgNPs. Very little zone of inhibition $(8 \mathrm{~mm})$ was observed in standard fluconazole against $C$. albicans MTCC183 indicating the development of resistance against drug. However, the AgNPs showed better inhibition (13 mm) in C. albicans MTCC183 as compared to fluconazole. According to Jiaxin Gao et al. the $C$. albicans gains azole resistance by altering sphingolipid composition via genetic alternation of the drug target Erg11. The reason for easily acquired resistance to multiple antifungal drugs by Candida spp. remains unidentified. However, a wide genome genetic screening has been conducted in detail for fluconazole resistance ${ }^{[34]}$. The percent resistance acquired by Candida spp. against fluconazole was also reported by Berkow EL and

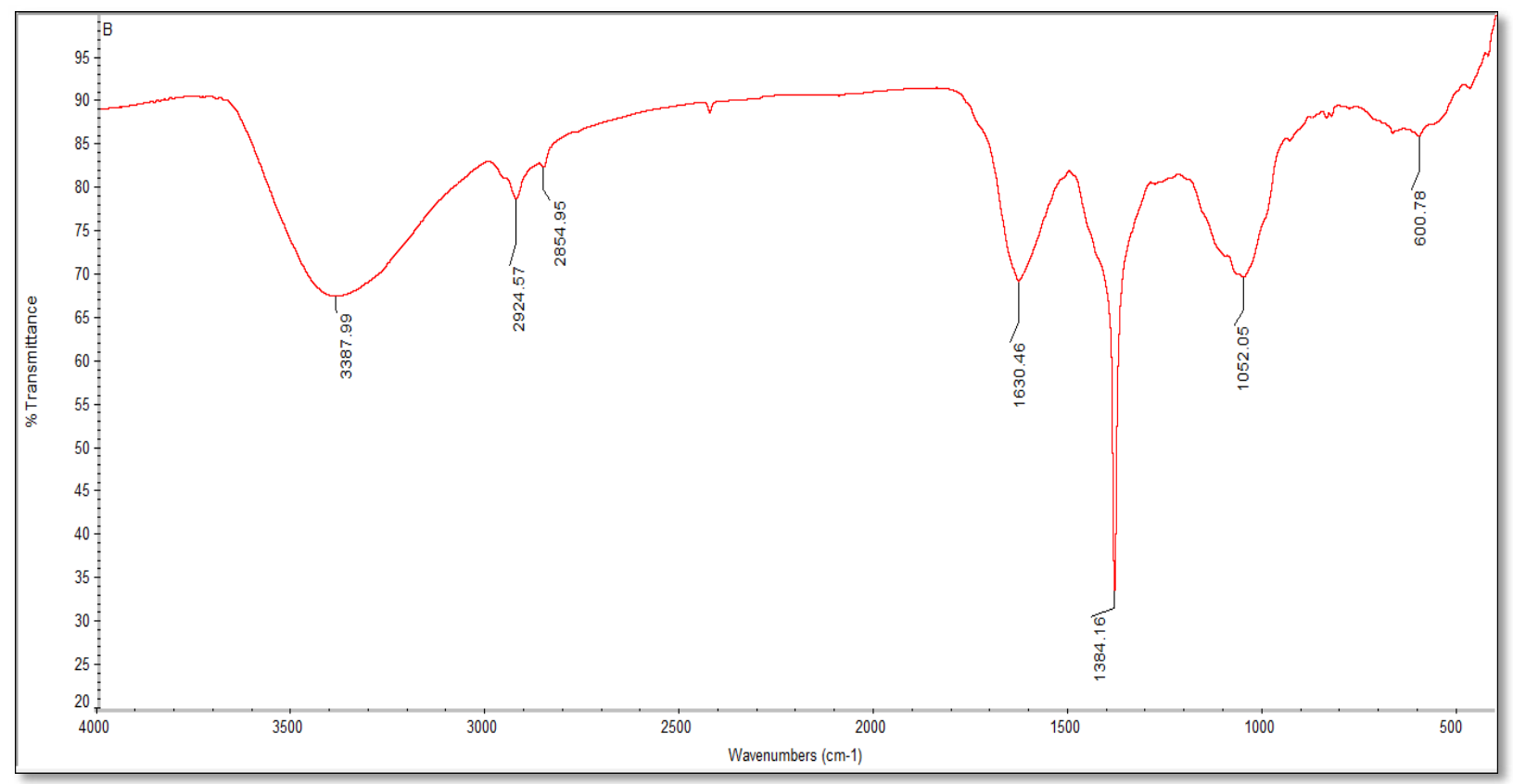

Fig. 5: FTIR pattern of AgNPs. 
TABLE 1: FTIR ABSORPTION PEAKS AND THEIR FUNCTIONAL GROUPS

\begin{tabular}{lc}
\hline Absorption peaks $\left(\mathrm{cm}^{-1}\right)$ & Functional groups \\
\hline 600.78 & A terminal alkaline C-H bending vibration \\
1052.05 & Si-O-Si stretching vibration of proteins \\
1384.16 & Monosubstituted alkynes \\
1630.46 & Amide bond-1 of polypeptide \\
2854.95 & Diol on ZnO nanoparticles \\
2924.57 & O-H stretching carboxylic acid \\
3387.99 & - OH stretching vibration band \\
\hline
\end{tabular}

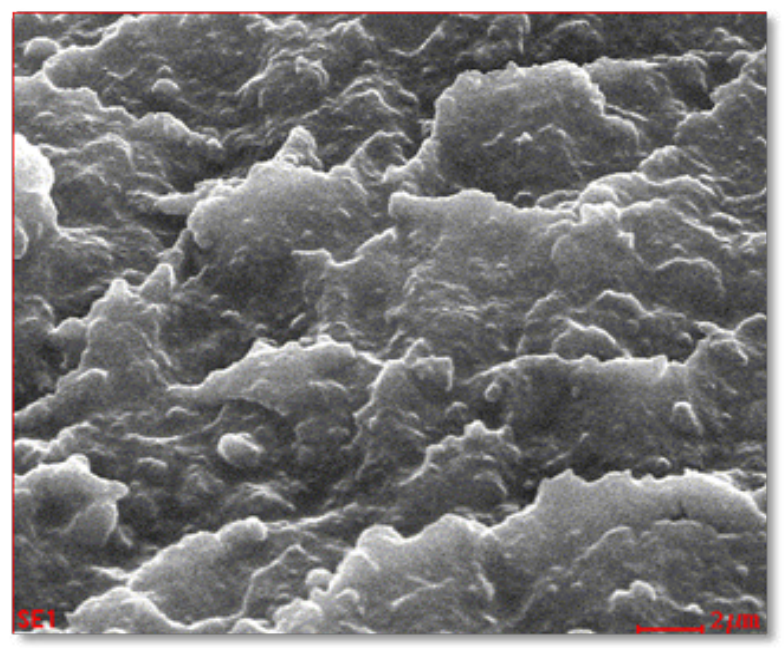

Fig. 6: SEM micrographs of AgNPs

Note: Morphological view of AgNPs by scanning electron microscopy (SEM) of reduced silver nanoparticles.

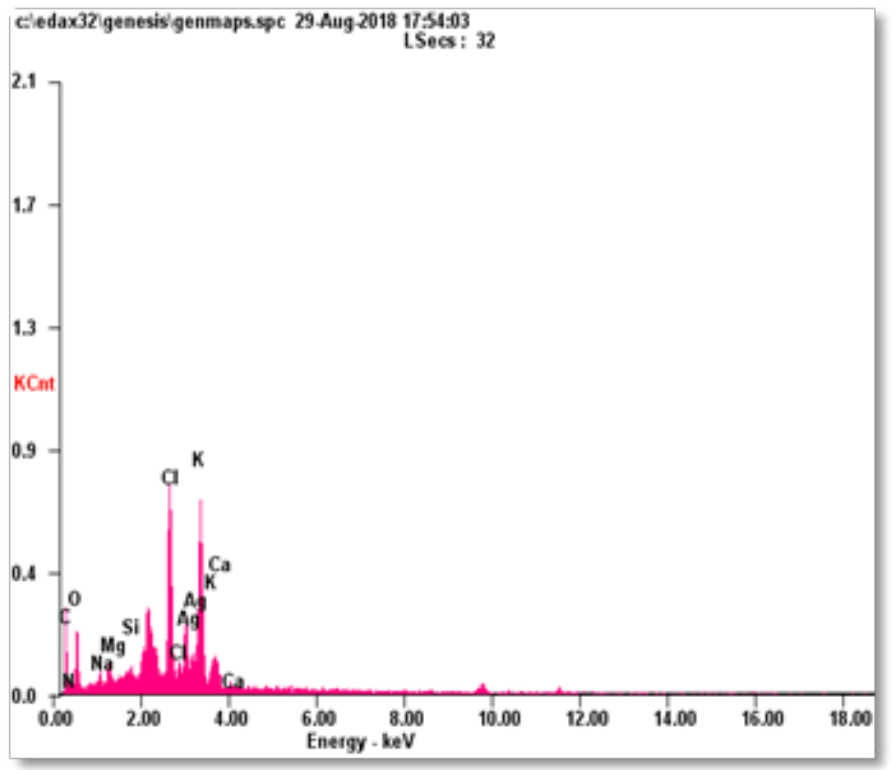

Fig. 7: EDX elemental analysis of AgNPs

TABLE 2: ANTICANDIDAL ACTIVITY OF SYNTHESIZED SILVER NANOPARTICLES

\section{ZOI in $\mathrm{mm}(\mathrm{mg} / \mathrm{ml})$}

Candida spp.

C. albicans MTCC 3017

C. albicans MTCC 1637

C. albicans MTCC183

C. tropicalis MTCC230

C. glabrata MTCC 3814
Fluconazole

15

15

08

12

17

AgNPs

$50 \mu \mathrm{l} \quad 100 \mu \mathrm{l}$

$13 \quad 14$

$15 \quad 14$

$13 \quad 13$

$09 \quad 12$

10

AgNO
06
03
03
08
03

Plant extract

DMSO

$\begin{array}{ll}- & - \\ - & - \\ - & - \\ - & - \\ - & -\end{array}$


Lockhart $^{[35]}$. The wheatgrass AgNPs exhibited good anti-fungal activity against Candida spp (fig. 8).

MIC of AgNPs performed by using two fold diluted concentration of AgNPs against five clinical isolates of Candida spp. to determine the minimum concentration that completely inhibit the visible growth of C. albicans MTCC3017, C. albicans MTCC1637, C. albicans MTCC183, C. tropicalis MTCC230 and C. glabrata MTCC3814. The MIC of AgNPs against tested organisms was found at $128 \mu \mathrm{g} / \mathrm{ml}$ against all test organisms except $C$. tropicalis MTCC230 (Table 3). A few Candida colonies were observed at $2,4,8,16,32$ and $64 \mu \mathrm{g} / \mathrm{ml}$ concentration and there is no visible growth of Candida strains at $128 \mu \mathrm{g} / \mathrm{ml}$. These results could be very much useful in designing the new anticandidal drug. The multiple applications of AgNPs in health care system have attracted the current researcher towards the synthesis, characterization and pharmacological properties of nanoparticels.

TABLE 3: MINIMUM INHIBITORY CONCENTRATION (MIC) OF AgNPS

\begin{tabular}{|c|c|c|c|}
\hline \multirow[b]{2}{*}{ Candida spp. } & \multicolumn{3}{|c|}{$M I C$ in $\mu \mathrm{g} / \mathrm{ml}$} \\
\hline & Fluconazole & AgNPs & Plant extract \\
\hline C. albicans MTCC 3017 & 16 & 128 & $>256$ \\
\hline C. albicans MTCC 1637 & 32 & 128 & $>256$ \\
\hline C. albicans MTCC183 & 64 & 128 & $>256$ \\
\hline C. tropicalis MTCC230 & 32 & $>256$ & $>256$ \\
\hline C. glabrata MTCC 3814 & 16 & 128 & $>256$ \\
\hline
\end{tabular}
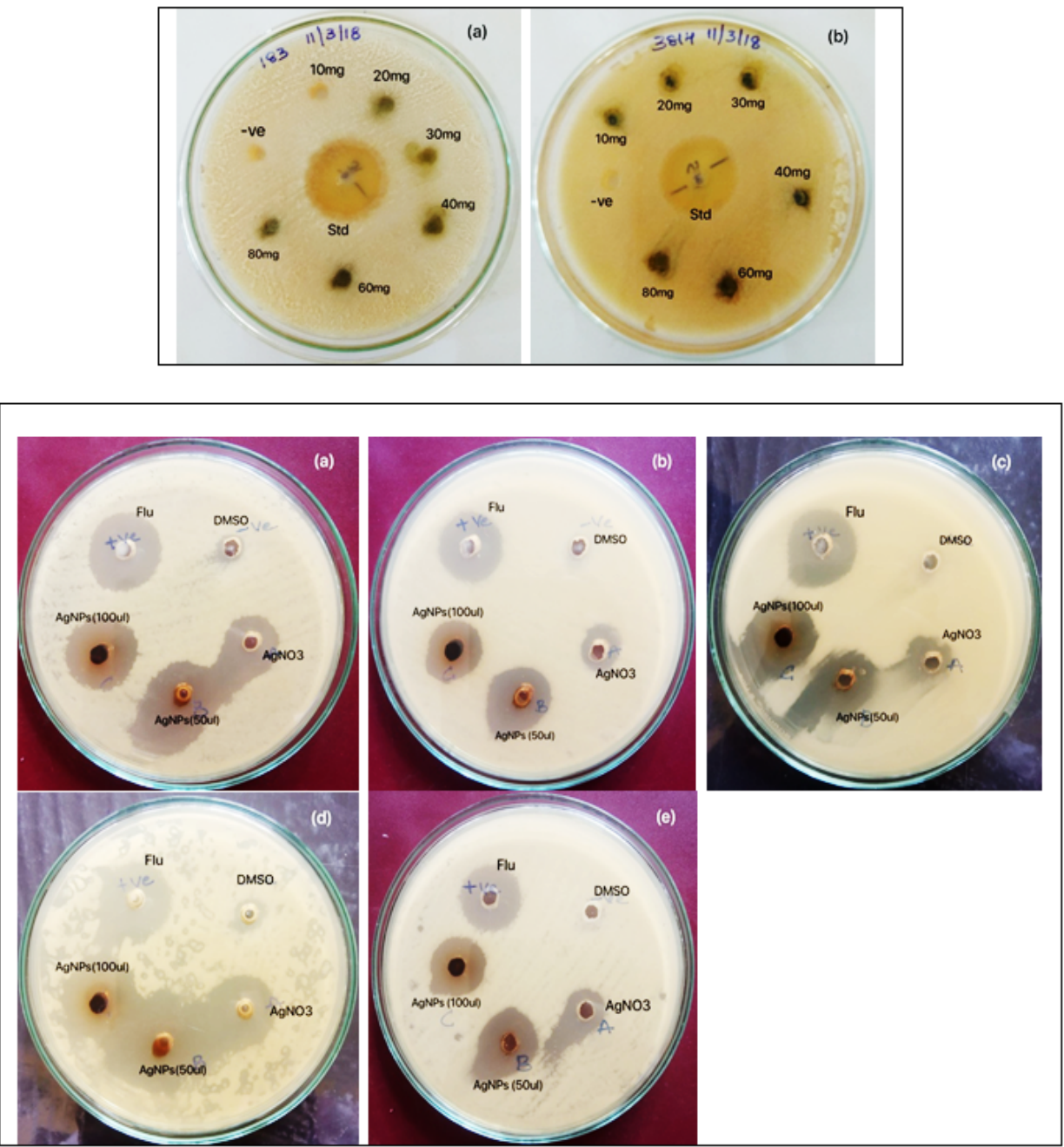

Fig. 8: Anticandidal activity of biosynthesized silver nanoparticles

Note: Anticandidal activity of wheat grass extract $(10 \mathrm{mg}, 20 \mathrm{mg}, 30 \mathrm{mg}, 40 \mathrm{mg}, 60 \mathrm{mg}$ and $80 \mathrm{mg} / \mathrm{ml}$ ) against (a) C. albicans MTCC183, (b) C. glabrata MTCC3814; Anticandidal activity: Flu (Fluconazole), DMSO (dimetyle sulfoxide), AgNO (Silver nitrate), AgNPs (Biosynthesized silver nanoparticles 50 $\mu \mathrm{l} \& 100 \mu \mathrm{l})$. (a) C. albicans MTCC3017, (b) C.albicans MTCC1637, (c) C. albicans MTCC183, (d) C. tropicalis MTCC230, (e) C. glabrata MTCC3814 


\section{Acknowledgements:}

The authors are thankful to the Department of Physics Gulbarga University Kalaburagi, SAIF IIT Madras and Dr. Shreenivasa Nayaka, Karnataka University Dharwad for their support in carrying out XRD, SEM with EDAX, FTIR and AFM analysis respectively.

\section{Conflict of interests:}

The authors declared no conflicts of interest.

\section{REFERENCES}

1. Sachin S, Vivek KS, Archana S, Shrivastav BR. Therapeutic potential of wheatgrass (Triticum aestivum L.) for the treatment of chronic diseases. South Asian J Exp Biol 2013;3(6):308-13.

2. Seth RK, Shah A, Shukla DN. Isolation and identification of soil fungi from wheat cultivated area of Uttar Pradesh. J Plant Pathol Microbiol 2016;7(11).

3. Pelton R. Alternatives in Cancer Therapy: The Complete Guide to Alternative Treatments. Simon and Schuster; 2009.

4. Mujoriya R, Bodla RB. A study on wheat grass and its nutritional value. Food Sci Qual Manag 2011;2:1-8.

5. Arya P, Kumar M. Chemoprevention by Triticum aestivum of mouse skin carcinogenesis induced by DMBA and croton oil-association with oxidative status. Asian Pac J Cancer Prev 2011;12(1):143-8.

6. Marwaha RK, Bansal D, Kaur S, Trehan A. Wheat grass juice reduces transfusion requirement in patients with thalassemia major: a pilot study. Indian Pediatr 2004;41(7):716-20.

7. Pole SN. Wheat grass juice in thalassemia. Indian pediatr 2006;43(1):79-80.

8. Soma M, Ashis M, Pinaki RG, Manoj K, Arpita G. The role of iron chelation activity of wheat grass juice in blood transfusion requirements of intermediate thalassaemia. ASH Annual Meeting and Exposition 2007;110:3289.

9. Das P, Mukhopadhyay A, Mandal S, Pal BC, Mishra R, Mukherjee $\mathrm{D}$, et al. In vitro studies of iron chelation activity of purified active ingredients extracted from Triticum aestivum Linn.(Wheat Grass). Eur J Med Plant 2012:113-24.

10. Caruthers SD, Wickline SA, Lanza GM. Nanotechnological applications in medicine. Curr Opin Biotechnol 2007;18(1):2630.

11. Mandal D, Bolander ME, Mukhopadhyay D, Sarkar G, Mukherjee $\mathrm{P}$. The use of microorganisms for the formation of metal nanoparticles and their application. Appl Microbiol Biotechnol 2006;69(5):485-92.

12. Kowshik M, Ashtaputre S, Kharrazi S, Vogel W, Urban J, Kulkarni SK, et al. Extracellular synthesis of silver nanoparticles by a silver-tolerant yeast strain MKY3. Nanotechnology 2002;14(1):95-100.

13. Mukherjee P, Ahmad A, Mandal D, Senapati S, Sainkar $\mathrm{SR}$, Khan MI, et al. Fungus-mediated synthesis of silver nanoparticles and their immobilization in the mycelial matrix: a novel biological approach to nanoparticle synthesis. Nano Lett 2001;1(10):515-9.

14. Iravani S. Green synthesis of metal nanoparticles using plants. Green Chem 2011;13(10):2638-50.

15. Yildiztekin M, Nadeem S, Yildiztekin F, Varol O, Ozler MA, Tuna AL. Green synthesis and characterization of silver nanoparticles from Crocus mathewii; a disremembered Turkish flowering plant. Indian J Pharm Sci 2017;79(4):536-43.

16. Pfaller MA, Diekema DJ. Epidemiology of invasive candidiasis: a persistent public health problem. Clin Microbiol Rev 2007;20(1):133-63.

17. Ganguly S, Mitchell AP. Mucosal biofilms of Candida albicans. Curr Opin Microbiol 2011;14:380-85.

18. Richard AC, Cornelius JC. Candida and Candidiasis. 2nd ed. Washington ASM Press; 2012.

19. Wisplinghoff H, Bischoff T, Tallent SM, Seifert H, Wenzel RP, Edmond MB. Nosocomial bloodstream infections in US hospitals: analysis of 24,179 cases from a prospective nationwide surveillance study. Clin Infect Dis 2004;39(3):30917.

20. Tournu H, Van Dijck P. Candida biofilms and the host: models and new concepts for eradication. Int J Microbiol 2012;1-16.

21. Mathé L, Van Dijck P. Recent insights into Candida albicans biofilm resistance mechanisms. Curr Genet 2013;59(4):25164 .

22. Berger TJ, Spadaro JA, Chapin SE, Becker RO. Electrically generated silver ions: quantitative effects on bacterial and mammalian cells. Antimicrob Agents Chemother 1976;9(2):357-58.

23. Logeswari P, Silambarasan S, Abraham J. Synthesis of silver nanoparticles using plants extract and analysis of their antimicrobial property. J Saudi Chem Soc 2015;19(3):311-7.

24. Al-Enazi NM, Awaad AS, Al-Othman MR, Al-Anazi NK, Alqasoumi SI. Isolation, identification and anti-candidal activity of filamentous fungi from Saudi Arabia soil. Saudi Pharm J 2018;26(2):253-7.

25. Kim SH, Lee HS, Ryu DS, Choi SJ, Lee DS. Antibacterial activity of silver-nanoparticles against Staphylococcus aureus and Escherichia coli. Microbiology and Biotechnol Lett 2011;39(1):77-85.

26. Banerjee P, Satapathy M, Mukhopahayay A, Das P. Leaf extract mediated green synthesis of silver nanoparticles from widely available Indian plants: synthesis, characterization, antimicrobial property and toxicity analysis. Bioresour Bioprocess 2014;1(1):1-3.

27. Dong C, Zhang X, Cai H, Cao C. Facile and one-step synthesis of monodisperse silver nanoparticles using gum acacia in aqueous solution. J Mol Liq 2014;196:135-41.

28. Prakash P, Gnanaprakasam P, Emmanuel R, Arokiyaraj S, Saravanan M. Green synthesis of silver nanoparticles from leaf extract of Mimusops elengi Linn. for enhanced antibacterial activity against multi drug resistant clinical isolates. Colloids Surf B Biointerfaces 2013;108:255-9.

29. Kumar PV, Pammi SV, Kollu P, Satyanarayana KV, Shameem U. Green synthesis and characterization of silver nanoparticles using Boerhaavia diffusa plant extract and their anti bacterial activity. Ind Crops Prod 2014;52:562-6.

30. Sarsar V, Selwal MK, Selwal KK. Biofabrication, characterization and antibacterial efficacy of extracellular silver nanoparticles using novel fungal strain of Penicillium atramentosum KM. J Saudi Chem Soc 2015;19(6):682-8.

31. Ahmed S, Saifullah, Ahmad M, Swami BL, Ikram S. Green synthesis of silver nanoparticles using Azadirachta indica aqueous leaf extract. J Radiat Res Appl Sci 2016;9(1):1-7.

32. Desai R, Mankad V, Gupta SK, Jha PK. Size distribution of silver nanoparticles: UV-visible spectroscopic assessment. Nanosci Nanotechnol Lett 2012;4(1):30-4.

33. He R, Qian X, Yin J, Zhu Z. Preparation of polychrome silver nanoparticles in different solvents. J Mater Chem 2002;12(12):3783-6. 
www.ijpsonline.com

34. Gao J, Wang H, Li Z, Wong AH, Wang YZ, Guo Y, et al. Candida albicans gains azole resistance by altering sphingolipid composition. Nat Commun 2018;9(1):1-4.
35. Berkow EL, Lockhart SR. Fluconazole resistance in Candida species: a current perspective. Infect Drug Resist 2017;10:23745 . 